\title{
Trends in treatment delays for patients with acute ST-elevation myocardial infarction treated with primary percutaneous coronary intervention
}

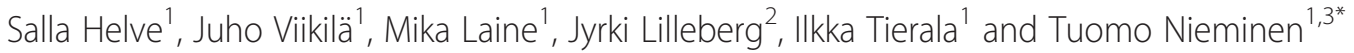

\begin{abstract}
Background: Treatment delay is an important prognostic factor for patients with acute ST-elevation myocardial infarction (STEMI) treated with primary percutaneous coronary intervention (PCI). We aimed to determine recent trends in these delays and factors associated with longer delays.

Methods: We compared two datasets collected in Helsinki University Central Hospital in 2007-2008 (HUS-STEMI I) and 2011-2012 (HUS-STEMI II), a total of 500 patients treated with primary PCI within 12 hours of the onset of symptoms.

Results: Delays of the emergency medical system (EMS) were longer in HUS-STEMI I than II (medians 81 vs. 67 min, respectively, $p<0.001$ ). Although door-to-balloon times were longer in the later dataset (33 vs. $48 \mathrm{~min}, \mathrm{p}<0.001$ ) most of the patients ( $75.3 \%$ vs. $62.8 \%$, respectively, $\mathrm{p}=0.010$ ) were treated within the recommendation ( $<60 \mathrm{~min}$ ) of the European Society of Cardiology (ESC). In HUS-STEMI II, patient arrival at the hospital during off-hours was associated with longer door-to-balloon time (40 and $57.5 \mathrm{~min}, \mathrm{p}=0.001$ ) and system delay (111 and $127 \mathrm{~min}$, $p=0.009$ ). However, in HUS-STEMI I, arrival time did not impact the delays. Longer system delay was associated with higher mortality rates.

Conclusions: Though the delays inside the hospital have increased they are still mostly within the ESC guidelines. Still, only about half of the patients are treated within a system delay of recommended two hours. Albeit our results are good in comparison with previous studies, further efforts for decreasing the delays particularly within the EMS should be established.
\end{abstract}

Keywords: Primary percutaneous coronary intervention, Prognosis, ST-segment elevation myocardial infarction, Treatment delays

\section{Background}

Total ischemic time is a significant predictor of outcome in patients with acute ST-elevation myocardial infarction (STEMI) [1-3]. Timely reperfusion therapy reduces mortality of patients with STEMI [1,4-7]. According to international guidelines, primary percutaneous coronary intervention $(\mathrm{PCI})$ is the primary choice of reperfusion therapy if $\mathrm{PCI}$ can be performed by an experienced team and within two hours of first medical contact (FMC)

\footnotetext{
* Correspondence: tuomo.nieminen@iki.fi

'Heart and Lung Center, Cardiology, Helsinki University Central Hospital, P.O. Box 340, Fl-00029 Helsinki, Finland

${ }^{3}$ Department of Internal Medicine, South Karelia Central Hospital, Lappeenranta, Finland

Full list of author information is available at the end of the article
}

[8,9]. In addition, the overall risk of the patient should be considered when choosing the reperfusion method [10]. Delay between the onset of symptoms and reperfusion therapy reflects the total ischemic time which is why the delay should be reduced as much as possible. However, reperfusion therapy inside the time limits of the international guidelines is seldom achieved in a majority of hospitals [11-13]. Although some earlier studies have reported significant decreases in door-to-balloon times over years, most of the latest studies have only shown limited improvement in treatment delays [11,12,14-16]. Previous studies have also indicated that the delays are longer during off-hours than during regular office hours $[15,17,18]$. 
The objective of this study was to determine the delays for STEMI patients treated with primary PCI in the Helsinki University Central Hospital $(\mathrm{HUCH})$, providing 24/7 PCI-service and being responsible for all primary PCIs in the hospital district of Helsinki and Uusimaa (HUS) in southern Finland. We compared two different datasets, HUS-STEMI I collected in 2007-2008 and HUS-STEMI II in 2011-2012, in order to determine whether there has been any improvement in delays within the last years. In addition, we assessed the variation in the delays between regular and off-hours. Finally, we determined whether longer delays had an effect on the patient outcome.

\section{Methods}

\section{Data collection}

The STEMI patients for the earlier dataset, HUS-STEMI I, were enrolled between June 13, 2007 and June 12, 2008 in the HUS area [19]. Patients were included if they had STEMI and lived permanently in the HUS district. They also had to give a written consent. The criteria for STEMI were symptoms of acute myocardial ischemia and ECG showing at least $2 \mathrm{~mm}$ ST-elevation $(1.5 \mathrm{~mm}$ for women) in at least two of the leads V1-V3 or at least $1 \mathrm{~mm}$ ST-elevation in other two adjacent leads (in leads V4-6, V8, V4R, I, aVL, II, III and aVF) or a new left bundle branch block (LBBB). To ensure complete coverage hospital files were also searched to find all additional STEMI patients treated in the HUS area during this time period. The patients who had not been recruited during their hospital stay were contacted later by letters and phone calls. The HUS-STEMI I dataset also included 176 patients treated with fibrinolysis and 78 patients who did not receive any primary reperfusion therapy; these were excluded from the present study.

The other dataset, HUS-STEMI II, comprises of all the STEMI patients treated with primary PCI in $\mathrm{HUCH}$ between January 1, 2011 and April 30, 2012. Patients were collected prospectively to a local STEMI-registry to determine the safety and efficacy of a new antithrombotic drug combination, enoxaparine-prasugrel-bivalirudin, introduced in the local STEMI treatment guidelines in the HUS area in autumn 2010. To be included patients had to meet the same criteria for STEMI as in the earlier dataset and be treated with primary PCI within 12 hours from the onset of pain. Patients treated with fibrinolysis were not included in the data. Eighty-one patients were excluded from the present study because they did not live permanently in the HUS area.

The primary PCI patients in HUS-STEMI I received aspirin $250 \mathrm{mg}$ p.o, enoxaparine $30 \mathrm{mg}$ i.v, abciximab bolus $0.25 \mathrm{mg} / \mathrm{kg}$ i.v. (or alternatively eptifibatide or tirofiban) and clopidogrel $600 \mathrm{mg}$ p.o. According to the new local guidelines, the patients in the HUS-STEMI II dataset were to receive aspirin $250 \mathrm{mg}$ p.o, enoxaparine $30 \mathrm{mg}$ i.v. and prasugrel $60 \mathrm{mg}$ p.o. upon FMC, and an infusion of bivalirudin in the course of PCI.

The final cohorts included 194 patients from HUSSTEMI I and 306 patients from HUS-STEMI II. Regardless of their differences, the two datasets are comparable. They both contain all STEMI patients treated with primary PCI in HUCH during the data collection period. In addition, the registration of data points was essentially similar.

The study was performed in accordance with the Declaration of Helsinki. The collection of HUS-STEMI I dataset was approved by the ethical board of the $\mathrm{HUCH}$ district, and the patients gave the informed consent to participate in the study. The HUS-STEMI II is a registry study, which does not need an ethical approval from the above-mentioned board. However, we received the appropriate approval needed for the registry study as well as the overall approval from our institution to perform the study.

\section{Guidelines for delays and definitions for time points}

Patient delay is the delay from the onset of symptoms to FMC. The time from FMC to the arrival at hospital constitutes the delay of the emergency medical system (EMS). The system delay refers to the sum of the EMS delay and door-to-balloon time within the hospital. The PCI time point was defined as the first balloon inflation. The total ischemic time is the sum of the patient delay and the system delay. We concentrated on the system delay and its components because it is more easily affected by organizational changes such as changes in EMS or hospital strategies. Patient delay can also be affected by recall bias meaning that a patient might be uncertain about the time of the onset of symptoms. According to the latest guidelines stated by the European Society of Cardiology (ESC) the system delay for primary PCI should be less than 90 minutes and for high-risk patients (early presenters within 2 hours or large anterior infarcts) less than 60 minutes. Door-to-balloon time in PCI-capable hospitals should be less than 60 minutes [8].

The time points for the assessment of delays used in this study were the onset of symptoms, first diagnostic ECG (considered as FMC), arrival at PCI providing $\mathrm{HUCH}$ hospital (Meilahti), the beginning of angiography and PCI. From these parameters, the patient delay, the delay of EMS, door-to-balloon time, the system delay and the overall delay were calculated.

The arrival time at the hospital was divided to groups based on whether patient arrived during regular or offhours in order to determine whether there was variation between the time groups. The definition for off-hours used in this study was weekdays between $4 \mathrm{pm}$ and 7 am, weekends and national holidays. 
The patient outcomes measured in this study were 90day all-cause mortality and major adverse cardiac event (MACE) within 90 days of the initial STEMI. The composite of MACE consisted of cardiovascular death, non-fatal myocardial infarction, ischemic or hemorrhagic stroke and unplanned new target vessel or non-target vessel revascularization. Myocardial infarction was defined according to current international guidelines [20]. Stroke was defined as any focal neurological deficit of ischemic or hemorrhagic origin lasting for longer than 24 hours.

\section{Statistical analysis}

Continuous data was expressed as median with interquartile range (IQR) and categorical data as percentages. Percentage of patients treated within the time limits recommended by ESC was calculated. Mann-Whitney U and $x^{2}$ tests were used for continuous and categorical variables, respectively. A linear regression analysis was used to evaluate the significance of factors possibly related to longer treatment delays. These factors included patient baseline characteristics, prior cardiovascular diseases, Killip class, hospital arrival time and patient related delay. In HUS-STEMI II we also analyzed whether there was a correlation between the delays and adherence to the new local guidelines (enoxaparine, prasugrel and bivalirudine). The delays and relationships were compared between the two datasets. A logistic regression analysis was used for binary covariates such as endpoints. $\mathrm{P}<0.05$ was considered statistically significant. Statistical analysis was performed with SPSS 15.0 (SPSS, Inc., Chicago, IL).

\section{Results}

A total of 500 patients were included in the analysis (Table 1). HUS-STEMI I had more patients with prior diagnosed hypertension or prior acute myocardial infarction (AMI). Otherwise the baseline characteristics for the datasets were similar. In addition, if each dataset was divided into groups based on hospital arrival in regular compared to off-hours, the two groups were similar with one exception: there were more patients with a previous stroke during off-hours in HUS-STEMI I.

\section{Changes in delays}

The median EMS delay was longer in HUS-STEMI I than II (81 vs. $67 \mathrm{~min}$, respectively, $\mathrm{p}<0.001$ ) (Figure 1). However, the median door-to-balloon time was longer in HUSSTEMI II than I (48 vs. 33 min, respectively, $\mathrm{p}<0.001$ ) with total system delays being virtually the same in both datasets (119.5 vs. $119 \mathrm{~min}$, respectively, $\mathrm{p}=0.549$ ). There were no significant changes in the patient delays or the total ischemic times, although the delays were numerically slightly longer in HUS-STEMI II.
Table 1 Baseline characteristics for both datasets

\begin{tabular}{lccc}
\hline & HUS-STEMI I & HUS-STEMI II & \\
& $\mathbf{n}=\mathbf{1 9 4}$ & $\mathbf{n}=\mathbf{3 0 6}$ & \\
& $\mathbf{\%}$ & $\mathbf{\%}$ & $\mathbf{p}$ \\
\hline Mean age, mean (SD) years & $64.8(12.9)$ & $64.3(14.0)$ & 0.920 \\
Age > 75 years & 23.7 & 26.1 & 0.542 \\
Male sex & 64.9 & 69.0 & 0.352 \\
Diabetes & 15.5 & 19.6 & 0.240 \\
Current smoker & 35.6 & 39.0 & 0.449 \\
Hypertension & 63.4 & 53.3 & 0.026 \\
Dyslipidemia & 44.8 & 41.5 & 0.462 \\
Renal dysfunction & 1.5 & 4.2 & 0.094 \\
AMl & 18.6 & 10.8 & 0.014 \\
Stroke & 8.8 & 6.5 & 0.354 \\
CABG & 4.1 & 5.2 & 0.573 \\
PCl & 9.8 & 13.4 & 0.227 \\
ASA & 23.2 & 26.8 & 0.367 \\
P2Y12 inhibitor & 2.1 & 3.9 & 0.250 \\
Warfarin & 9.3 & 8.8 & 0.863 \\
Anterior infarct & 46.8 & 53.6 & 0.143 \\
Killip class 2-4 & 12.4 & 18.0 & 0.096 \\
Admission at regular hours & 41.5 & 40.8 & 0.888 \\
\hline Val s a & & &
\end{tabular}

Values are percentages with the exception of age.

$A M I$, acute myocardial infarction; $A S A$, acetosalicylic acid; $C A B G$, coronary artery bypass graft; $P C l$, percutaneous coronary intervention.

\section{Guideline adherence}

Recommendations for treatment delays were quite poorly achieved in both HUS-STEMI I and II (Table 2). System delay was less than 90 minutes in only approximately one fourth of the cases. System delay of less than 120 minutes was achieved in a half of the cases; the differences between datasets were not statistically significant. Regarding the achievement of the target time frame of 60 minutes for EMS delay, a clear improvement was seen between the datasets. In HUS-STEMI II 41.0\% of patients achieved the target time frame as opposed to $24.7 \%$ in HUS-STEMI I. The delays inside the hospital were more often within the recommended time limits (<60 min) in both datasets (Table 2).

\section{Factors associated with delays}

In HUS-STEMI I, previous myocardial infarction was associated with shorter EMS delay (Table 3) and previous stroke with longer EMS delay. In addition, if patient related delay was more than 2 hours, the system delay was also longer.

In HUS-STEMI II, patient arrival at hospital during off-hours was strongly associated with longer system delay and door-to-balloon time (Tables 3 and 4). Patients treated according to the new antithrombotic medication 


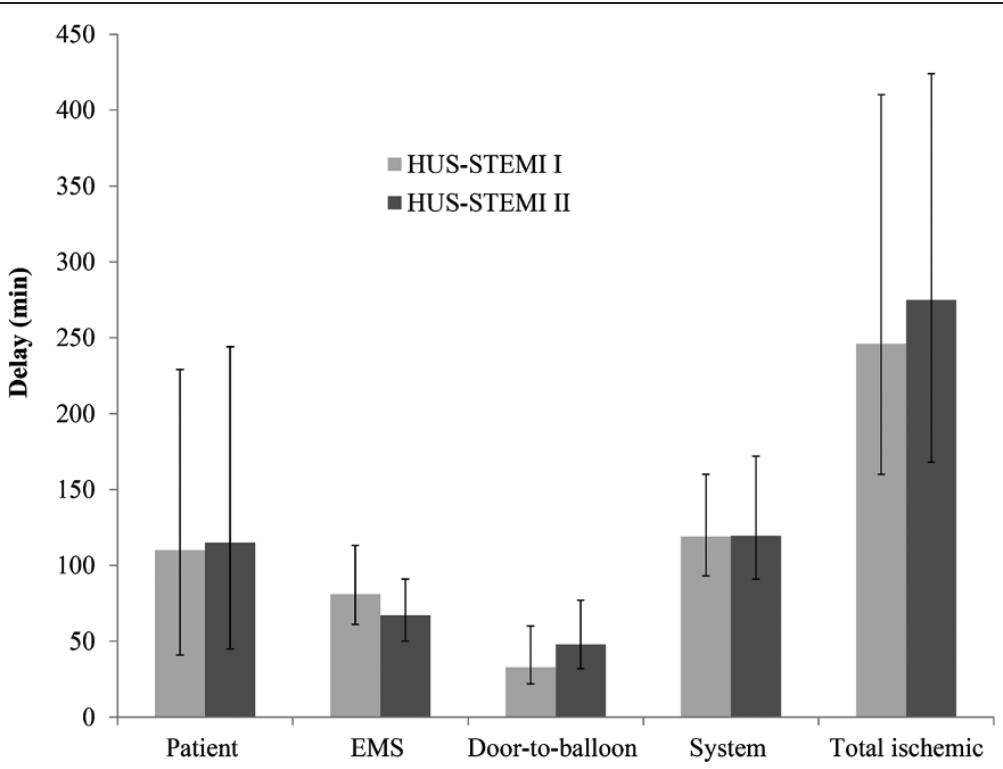

Figure 1 Median delays ( $\mathrm{min}$ ) with inter-quartile ranges.

protocol had shorter system delays and EMS delays. Treatment according to new guidelines had no effect on the door-to-balloon time. In addition, Killip class 2-4, when admitted to the hospital, was associated with longer door-to-balloon time in adjusted but not in unadjusted logistic regression.

The EMS delay was significantly longer in HUSSTEMI I than II during both on- and off-hours. On the other hand, the door-to-balloon time was longer in HUS-STEMI II during off-hours.

\section{Treatment delays and prognosis}

There was no significant difference in the incidence of MACE or death within 90 days between the datasets. The occurrence of MACE was numerically slightly smaller in HUS-STEMI I than II but this was not statistically significant $(11.4 \%$ and $14.9 \%$, respectively, $\mathrm{p}=$ 0.252). Mortality in HUS-STEMI I and II was $10.5 \%$ and $10.8 \%$, respectively $(\mathrm{p}=0.897)$.

Table 2 Guideline adherence: proportion of the delays within the recommended time limits

\begin{tabular}{lccc}
\hline Delay & HUS-STEMI I & HUS-STEMI II & \\
& \% & \% & p \\
\hline Patient delay $<120$ min & 55.8 & 50.8 & 0.290 \\
EMS delay $<60$ min & 24.7 & 41.0 & $<0.001$ \\
Door-to-balloon time $<60$ min & 75.3 & 62.8 & 0.010 \\
System delay $<90$ min & 22.0 & 25.0 & 0.499 \\
System delay $<120$ min & 52.0 & 50.4 & 0.761 \\
\hline
\end{tabular}

Time limit recommendations by the European Society of Cardiology (ESC). $E M S$, emergency medical system.
Longer door-to-balloon time ( $>60 \mathrm{~min})$ and longer system delay $(>90 \mathrm{~min})$ were the only time delay factors that had any effect on the incidence of MACE within 90 days after the STEMI. In unadjusted analysis, $7.9 \%$ of the patients with a door-to-balloon time less than $60 \mathrm{mi}-$ nutes had a MACE within 90 days of the STEMI compared to $15.7 \%$ of the patients with longer than $60 \mathrm{~min}$ door-to-balloon time $(\mathrm{p}=0.018)$. The median door-toballoon time for patients who had a MACE within 90 days was 60 minutes as opposed to 41 minutes in those without MACE $(\mathrm{p}=0.028)$. Of the patients treated within the system delay of 90 minutes $2.2 \%$ had a MACE within 90 days compared to $13.1 \%$ for the patients with system delay over 90 minutes $(\mathrm{p}=0.003)$. However, only the association between the system delay and 90-day MACE was statistically significant in regression analysis adjusted to baseline characteristics.

In unadjusted analysis, age $(\mathrm{p}<0.001)$, previous AMI $(\mathrm{p}=0.005)$, previous stroke $(\mathrm{p}=0.029)$, diabetes $(\mathrm{p}=$ $0.001)$, Killip class $2-4(\mathrm{p}<0.001)$ were other factors that had a link with 90-day MACE. When adjusted to baseline characteristics, only diabetes and Killip 2-4 were associated with higher incidence of 90-day MACE along with system delay.

Regarding the 90-day mortality, patient related delay was the only time delay factor that had a link with the mortality: in the surviving patient group the median patient related delay was 116 minutes as opposed to 67.5 minutes in the other group $(\mathrm{p}=0.044)$. Yet, this correlation was not statistically significant when adjusted to baseline characteristics.

Other factors associated with 90-day mortality when analyzed individually were age $(\mathrm{p}<0.001)$, sex $(\mathrm{p}=$ 
Table 3 Association of patient characteristics to the delays in multivariable linear regression

\begin{tabular}{|c|c|c|c|c|c|c|c|c|c|c|c|c|}
\hline & \multicolumn{6}{|c|}{ HUS-STEMI I } & \multicolumn{6}{|c|}{ HUS-STEMI II } \\
\hline & \multicolumn{2}{|c|}{ EMS delay } & \multicolumn{2}{|c|}{ Door-to-balloon } & \multicolumn{2}{|c|}{ System delay } & \multicolumn{2}{|c|}{ EMS delay } & \multicolumn{2}{|c|}{ Door-to-balloon } & \multicolumn{2}{|c|}{ System delay } \\
\hline & Beta & $p$ & Beta & $p$ & Beta & 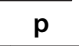 & Beta & $p$ & Beta & $p$ & Beta & $p$ \\
\hline Age & 0.082 & 0.394 & 0.132 & 0.235 & 0.139 & 0.184 & -0.007 & 0.915 & -0.028 & 0.705 & -0.039 & 0.596 \\
\hline Sex & -0.048 & 0.564 & -0.073 & 0.445 & -0.034 & 0.709 & -0.036 & 0.555 & 0.010 & 0.884 & 0.008 & 0.899 \\
\hline Smoking & 0.095 & 0.308 & 0.112 & 0.295 & 0.169 & 0.096 & -0.085 & 0.192 & 0.019 & 0.788 & -0.050 & 0.489 \\
\hline Post-Ml & -0.198 & 0.025 & 0.058 & 0.566 & -0.163 & 0.091 & 0.089 & 0.166 & 0.047 & 0.497 & 0.090 & 0.193 \\
\hline Post-stroke & 0.184 & 0.030 & -0.059 & 0.545 & 0.164 & 0.073 & -0.072 & 0.250 & -0.066 & 0.331 & -0.089 & 0.188 \\
\hline Diabetes & 0.152 & 0.058 & 0.070 & 0.459 & 0.134 & 0.134 & -0.064 & 0.316 & 0.003 & 0.966 & -0.003 & 0.963 \\
\hline Hypertension & -0.048 & 0.565 & -0.002 & 0.987 & -0.046 & 0.612 & 0.037 & 0.586 & -0.076 & 0.295 & -0.084 & 0.248 \\
\hline Dyslipidemia & -0.034 & 0.686 & 0.097 & 0.317 & 0.032 & 0.725 & -0.012 & 0.851 & 0.174 & 0.016 & 0.149 & 0.038 \\
\hline Anterior infarct & -0.092 & 0.235 & -0.028 & 0.753 & -0.026 & 0.761 & 0.047 & 0.433 & -0.014 & 0.831 & 0.026 & 0.689 \\
\hline Killip class $2-4$ & -0.126 & 0.116 & -0.056 & 0.541 & -0.084 & 0.327 & -0.052 & 0.404 & 0.141 & 0.039 & 0.073 & 0.278 \\
\hline Regular hours & -0.102 & 0.202 & -0.003 & 0.974 & -0.097 & 0.260 & -0.011 & 0.851 & -0.204 & 0.002 & -0.167 & 0.010 \\
\hline Patient related delay > $120 \mathrm{~min}$ & 0.215 & 0.101 & 0.059 & 0.702 & 0.321 & 0.027 & 0.159 & 0.099 & 0.017 & 0.877 & 0.063 & 0.556 \\
\hline New treatment protocol & & & & & & & -0.178 & 0.003 & -0.089 & 0.174 & -0.18 & 0.006 \\
\hline
\end{tabular}

0.042), previous AMI ( $\mathrm{p}=0.017)$, previous stroke $(\mathrm{p}<$ $0.001)$, diabetes $(\mathrm{p}=0.001)$ and Killip class $2-4(\mathrm{p}<$ $0.001)$. When adjusted to baseline characteristics, only age $(\mathrm{p}=0.001)$, previous stroke $(\mathrm{p}=0.027)$, diabetes $(\mathrm{p}=$ $0.011)$ and Killip class $2-4(\mathrm{p}<0.000)$ were linked with higher 90-day mortality.

\section{Discussion}

The delays

The unexpected finding in this study was that door-toballoon times were longer in 2011-2012 than 20072008. On the other hand, the EMS delays had become shorter in the course of years, although still being essentially longer than the in-hospital delays. As the system delay consists of the EMS delay and the delay inside the hospital, the related changes obliterated each other and the system delays between the compared datasets were similar.

Even though the in-hospital delay was longer in the latter than in the earlier dataset, both groups achieved the guidelines for door-to-balloon times quite well and the local delays are short in international comparison. Although being 15 minutes longer than in the earlier dataset, the median door-to-balloon time of 48 minutes in HUS-STEMI II is clearly within the recommendation of 60 minutes [8]. As many as $75.3 \%$ of patients were treated within 60 minutes in HUS-STEMI I, while the same target was reached in $62.8 \%$ of the HUS-STEMI II patients (Table 2). Some earlier studies have reported significant improvement in the door-to-balloon times over time but the results are from the early years of primary PCI, when the decrease in delays was more expectable $[15,16]$. More recent studies have shown less improvement in door-to-balloon times over time. In a study from a multinational registry GRACE, the doorto-balloon times remained practically unchanged (75-84 minutes) during the study period from 1999 to 2006 with an exception of the year 1999 when the median door-to-balloon time was 99 minutes [11]. However, a recent study of the large CathPCI registry from the USA

Table 4 Median delays (inter-quartile range) in regular vs. off-hours

\begin{tabular}{|c|c|c|c|c|c|c|}
\hline & \multicolumn{3}{|c|}{ HUS-STEMI I } & \multicolumn{3}{|c|}{ HUS-STEMI II } \\
\hline & Regular hours & Off-hours & & Regular hours & Off-hours & \\
\hline & $n=72$ & $n=108$ & $p$ & $n=123$ & $n=178$ & $p$ \\
\hline Patient delay & $113(41-246)$ & $109(42-221)$ & 0.972 & $117(38-243)$ & $110.5(48-246)$ & 0.612 \\
\hline EMS delay & $83(60-112)$ & $80(62-121)$ & 0.669 & $64(47-89)$ & $68.5(52-94)$ & 0.270 \\
\hline Door-to-balloon time & $37(25-63)$ & $31(21-60)$ & 0.464 & $40(29-61)$ & $57.5(34-87)$ & 0.001 \\
\hline System delay & $120.5(92-152)$ & $118.5(92-174)$ & 0.945 & $111(87-166)$ & $127(105-182)$ & 0.009 \\
\hline Total ischemic time & $227.5(161-398)$ & 255 (159-429) & 0.597 & $263.5(150-407)$ & 290 (189-439) & 0.064 \\
\hline
\end{tabular}

EMS, emergency medical system. 
showed significant improvement in door-to-balloon times over the study period: median door-to-balloon times decreased from $83 \mathrm{~min}$ to $67 \mathrm{~min}$ and the percentage of patients treated within 90 minutes increased from $60 \%$ to $83 \%$ from 2005 to 2009 [21].

The adherence to recommended time limits was poorer in other delays than door-to-balloon. The EMS delay has shrunk over time, but still only $41 \%$ of patients were transported to the PCI hospital in 60 minutes. The distances in the HUS area are relatively short with about two thirds of population being gathered in the city of Helsinki and its suburbs with up to $20-30 \mathrm{~km}$ distance to the Meilahti hospital of $\mathrm{HUCH}$. The longest distances to the Meilahti hospital are about $100 \mathrm{~km}$.

The median system delay in both datasets was a minute short of two hours. Only $22 \%$ in HUS-STEMI I and $25 \%$ in HUS-STEMI II were treated within 90 minutes (Table 2). The results from a US report from the National Registry of Myocardial Infarction from 1999 to 2002 were quite similar showing no substantial improvement in average treatment times: the percentage of patients with a system delay less than 90 minutes was 35\% in 1999 and increased by 2\% in 2002 [12]. Another study that described the delays in 30 European countries had median system delays of 60 to 177 minutes [13]. The system delay of our study is placed just in the middle of these European results. In our study, the majority of system delay is composed of the EMS delay, thus the efforts to decrease the delays should be focused on EMS.

Patient related delay was quite long in both datasets, medians being 110 vs. 115 minutes in former vs. later dataset. This forms almost a half of the total ischemic time, which is why attempts for reducing this delay should be established. Public campaigns have been effective for the recognition of the common symptoms of a stroke [22,23]; a similar strategy would most probably increase the awareness of the symptoms and shorten the delays in the context of AMI.

In a Swedish study, which analyzed the trends in the treatment of STEMI patients from 1996 to 2007, the total ischemic times first increased from $185 \mathrm{~min}$ to $216 \mathrm{~min}$ and then decreased again to 203 min over the study period. Even the present study demonstrated an increasing tendency for the delays over time. The total ischemic times in our study were considerably longer, $246 \mathrm{~min}$ and $275 \mathrm{~min}$ in HUS-STEMI I and II, respectively. However, further comparison between these studies is not possible because the Swedish study does not categorize the different components of the total ischemic time [14].

\section{Factors associated with delays}

Presentation to the hospital during off-hours seemed to be strongly associated with longer delays in HUS-STEMI
II. The difference in door-to-balloon times between regular and off-hours was 17.5 minutes and, correspondingly, in system delays 16 minutes. During off-hours the angiography team is on-call so it could be expected that the delays inside the hospital are longer than in the regular hours. The results from previous studies assessing the variation in treatment delays between regular and off-hours are quite similar to our results from HUSSTEMI II. Reported door-to-balloon times have been 21-25 minutes longer during off- than on-hours $[15,16]$. Interestingly, hospital presentation time did not affect the delays in the HUS-STEMI I dataset. The difference in the impact of off-hours presentation on the inhospital delays between the datasets might reflect the delegation of night-time initial STEMI consultation calls from interventional cardiologist to the physician in the coronary care unit in $\mathrm{HUCH}$; this reorganization occurred after the HUS-STEMI I period. The interventional cardiologists participating in the off-hours PCI procedures were virtually the same during both study periods and all of them live within 30 minutes from the hospital.

Patients treated according to the new local guidelines of antithrombotic medication also had shorter system and EMS delays. Treatment according to the new guidelines did not affect the door-to-balloon time. Therefore, the new protocol does not seem to cause any additional delay either inside the hospital or in the EMS.

In HUS-STEMI I, patients who waited for more than 2 hours before contacting the EMS had longer system delays. This may reflect less specific symptoms in these patients, which would lengthen the delays in different steps.

\section{Endpoints}

The 90-day mortality and the occurrence of major adverse cardiac event (MACE) in 90 days were similar in the two datasets. This is expected based on the fact that there were no significant differences in the system delays or total ischemic times. The small numerical decrease in the mortality may reflect development in other treatment for the STEMI patients. Longer system delay was associated with higher mortality rates in our study which is in accordance with previous studies $[1,3,7]$.

Medication given prior and/or during the PCI may influence the mortality [24]. In our data, treatment according to new guidelines did not affect 90-day MACE or mortality.

\section{Strengths and limitations of this study}

Both datasets contained all STEMI patients treated with primary PCI in $\mathrm{HUCH}$ during the data collection period. Thus, the study population represents the true STEMI population of the HUS area. An observational study 
cannot prove causality between the factors associated with delays or the endpoints. Furthermore, there were so few endpoints that the correlation between the delays and endpoints could not be analyzed reliably.

\section{Conclusions}

Door-to-balloon times have become longer but are still relatively well within the limits of the European guidelines. The EMS delays have become shorter but are still long in comparison to door-to-balloon times. Arrival at hospital during off-hours was the only factor clearly associated with longer delays inside the hospital suggesting that changes in the hospital strategies during off-hours should be considered.

\section{Competing interests}

The authors declare that they have no competing interests.

\section{Authors' contributions}

$\mathrm{SH}$ participated in the design of the study, performed the statistical analysis and drafted the manuscript. JV, ML, JL and IT participated in the design of the study and the data collection and revised the manuscript critically. TN supervised the study, participated in its design and coordination and helped to draft the manuscript. All authors read and approved the final manuscript.

\section{Acknowledgements}

We thank RN Tomi Nyman for his contributions to the study.

\author{
Author details \\ ${ }^{1}$ Heart and Lung Center, Cardiology, Helsinki University Central Hospital, P.O. \\ Box 340, FI-00029 Helsinki, Finland. 'Department of Internal Medicine, \\ Hyvinkää Hospital, Hyvinkää, Finland. ${ }^{3}$ Department of Internal Medicine, \\ South Karelia Central Hospital, Lappeenranta, Finland.
}

Received: 15 March 2014 Accepted: 14 August 2014

Published: 10 September 2014

\section{References}

1. De Luca G, Suryapranata H, Ottervanger JP, Antman EM: Time delay to treatment and mortality in primary angioplasty for acute myocardial infarction, every minute counts. Circulation 2004, 109:1223-1225.

2. Brodie BR, Webb J, Cox DA, Qureshi M, Kalynych A, Turco M, Schultheiss HP, Dulas D, Rutherford B, Antoniucci D, Stuckey T, Krucoff M, Gibbons R, Lansky A, Na Y, Mehran R, Stone GW, EMERALD investigators: Impact of time to treatment on myocardial reperfusion and infarct size with primary percutaneous coronary intervention for acute myocardial infarction (from the EMERALD trial). Am J Cardiol 2007, 99:1680-1686.

3. Shiomi H, Nakagawa Y, Morimoto T, Furukawa Y, Nakano A, Shirai S, Taniguchi R, Yamaji K, Nagao K, Suyama T, Mitsuoka H, Araki M, Takashima $H$, Mizoguchi T, Eisawa H, Sugiyama S, Kimura T, CREDO-Kyoto AMI investigators: Association of onset to balloon and door to balloon time with long term clinical outcome in patients with ST elevation acute myocardial infarction having primary percutaneous coronary intervention: observational study. BMJ 2012, 344:e3257.

4. Cannon CP, Gibson CM, Lambrew CT, Shoultz DA, Levy D, French WJ, Gore JM, Weaver WD, Rogers WJ, Tiefenbrunn AJ: Relationship of symptom-onset-to-balloon time and door-to-balloon time with mortality in patients undergoing angioplasty for acute myocardial infarction. JAMA 2000, 283:2941-2947.

5. Brodie BR, Gersh BJ, Stuckey T, Witzenbichler B, Guagliumi G, Peruga JZ, Dudek D, Grines CL, Cox D, Parise H, Prasad A, Lansky AJ, Mehran R, Stone GW: When is door to balloon time critical? Analysis from the HORIZONS-AMI (Harmonizing outcomes with revascularization and stents in acute myocardial infarction) and CADILLAC (Controlled abciximab and device investigation to lower late angioplasty complications) trials. J Am Coll Cardio/ 2010, 56:407-413.
6. McNamara RL, Wang Y, Herrin J, Curtis JP, Bradley EH, Magid DJ, Peterson ED, Blaney M, Frederick PD, Krumholtz HM, NRMI Investigators: Effect of door-to-balloon time on mortality in patients with STsegment elevation myocardial infarction. J Am Coll Cardiol 2006, 47:2180-2186

7. Terkelsen CJ, Sørensen JT, Maeng M, Jensen LO, Tilsted H, Trautner S, Vach W, Johnsen SP, Thuesen L, Lassen JF: System delay and mortality among patients with STEMI treated with primary percutaneous coronay intervention. JAMA 2010, 304(7):763-771.

8. Steg PG, James SK, Atar D, Badano LP, Lundqvist CB, Borger MA, Di Mario C, Dickstein K, Ducrocq G, Fernandez-Aviles F, Gershlick AH, Giannuzzi P, Halvorsen S, Huber K, Juni P, Kastrati A, Knuuti J, Lenzen MJ, Mahaffey KW, Valgimigli M, Van-'t Hof A, Widimsky P, Zahger D: ESC Guidelines for the management of acute myocardial infarction in patients presenting with ST-segment elevation: The Task Force on the management of STsegment elevation acute myocardial infarction of the European Society of Cardiology (ESC). Eur Heart J 2012, 33(20):2569-2629.

9. Boersma E, the Primary Coronary Angioplasty vs. Thrombolysis (PCAT)-2 Trialists' Collaborative Group: Does time matter? A pooled analysis of randomized clinical trials comparing primary percutaneous coronary intervention and in-hospital fibrinolysis in acute myocardial infarction patients. Eur Heart J 2006, 27:779-788.

10. Pinto DS, Kirtane AJ, Nallamothu BK, Murphy SA, Cohen DJ, Laham RJ, Cutlip DE, Bates ER, Frederick PD, Miller DP, Carrozza JP Jr, Antman EM, Cannon CP, Gibson CM: Hospital delays in reperfusion for ST-elevation myocardial infarction: implications when selecting a reperfusion strategy. Circulation 2006, 114:2019-2025.

11. Eagle KA, Nallamothu BK, Mehta RH, Granger CB, Steg PG, Van de Werf $F$ López-Sendón J, Goodman SG, Quill A, Fox KA, Global Registry of Acute Coronary Events (GRACE) Investigators: Trends in acute reperfusion therapy for ST-segment elevation myocardial infarction from 1999 to 2006: we are getting better but we have got a long way to go. Eur Heart J 2008, 29:609-617.

12. McNamara RL, Herrin J, Bradley EH, Portnay EL, Curtis JP, Wang Y, Magid DJ, Blaney M, Krumholz HM, NRMI Investigators: Hospital improvement in time to reperfusion in patients with acute myocardial infarction, 1999-2002. J Am Coll Cardiol 2006, 47(1):45-51.

13. Widimsky P, Wijns W, Fajadet J, de Belder M, Knot J, Aaberge L, Andrikopoulos G, Baz JA, Betriu A, Claeys M, Danchin N, Djambazov S, Erne P, Hartikainen J, Huber K, Kala P, Klinceva M, Kristensen SD, Ludman P, Ferre JM, Merkely B, Milicic D, Morais J, Noc M, Opolski G, Ostojic M, Radovanovic D, De Servi S, Stenestrand U, Studencan M, et al: European Association for Percutaneous Cardiovascular Interventions: Reperfusion therapy for ST elevation acute myocardial infarction in Europe: description of the current situation in 30 countries. Eur Heart J 2012, 31(8):943-957

14. Jernberg T, Johanson P, Held C, Svennblad B, Lindbäck J, Wallentin L, SWEDEHEART/RIKS-HIA: Association between adoption of evidence-based treatment and survival for patients with ST-elevation myocardial infarction. JAMA 2011, 305(16):1677-1684.

15. Angeja BG, Gibson CM, Chin R, Frederick PD, Every NR, Ross AM, Stone GW, Barron HV, Participants in the National Registry of Myocardial Infarction 2-3: Predictors of door-to-balloon delay in primary angioplasty. Am J Cardiol 2002, 89:1156-1161.

16. Gibson CM, Pride YB, Frederic PD, Pollack CV Jr, Canto JG, Tiefenbrunn AJ, Weaver WD, Lambrew CT, French WJ, Peterson ED, Rogers WJ: Trends in reperfusion strategies, door-to-needle and door-to-balloon times, and in-hospital mortality among patients with ST-segment elevation myocardial infarction enrolled in the National Registry of Myocardial Infarction from 1990 to 2006. Am Heart J 2008, 156:1035-1044.

17. Magid DJ, Wang Y, Herrin J, McNamara RL, Bradley EH, Curtis JP, Pollack CV $\mathrm{Jr}$, French WJ, Blaney ME, Krumholz HM: Relationship between time of day, day of week, timeliness of reperfusion and in hospital mortality for patients with acute ST-segment elevation myocardial infarction. JAMA 2005, 294:803-812.

18. Blakenship JC, Skelding KA, Scott TD, Berger PB, Parise H, Brodie BR, Dudek D, Möckel M, Lansky AJ, Mehran R: Predictors of reperfusion delay in patients with acute myocardial infarction undergoing primary percutaneous coronary intervention from the HORIZONS-AMI trial. Am J Cardiol 2010, 106:1527-1533. 
19. Vikilä J, Lilleberg J, Tierala I, Syvänne M, Kupari M, Salomaa V, Nieminen MS, the HUS-STEMI Investigators: Outcome up to one year following different reperfusion strategies in acute ST-segment elevation myocardial infarction: The Helsinki-Uusimaa Hospital District registry of ST-Elevation Acute Myocardial Infarction (HUS-STEMI). Eur Heart J 2013, 2(4):371-378.

20. Thygesen K, Alpert JS, Jaffe AS, Simoons ML, Chaitman BR, White HD, Writing Group on the Joint ESC/ACCF/AHA/WHF Task Force for the Universal Definition of Myocardial Infarction: Third universal definition of myocardial infarction. Eur Heart J 2012, 33(20):2551-2567.

21. Menees DS, Peterson ED, Wang Y, Curtis JP, Messenger JC, Rumsfeld JS, Gurm HS: Door-to-balloon time and mortality among patients undergoing primary PCl. N Engl J Med 2013, 369:901-909.

22. Robinson TG, Reid A, Haunton VJ, Wilson A, Naylor AR: The face arm speech test: does it encourage rapid recognition of important stroke warning symptoms? Emerg Med J 2013, 30(6):467-471.

23. Silver FL, Rubini F, Black D, Hodgson CS: Advertising strategies to increase public knowledge of the warning signs of stroke. Stroke 2003, 34:1965-1969.

24. Prati F, Petronio S, Van Boven AJ, Tendera M, De Luca L, de Belder MA, Galassi AR, Imola F, Montalescot G, Peruga JZ, Barnathan ES, Ellis S, Savonitto S, FINESSE-ANGIO substudy investigators: Evaluation of infarct-related coronary artery patency and microcirculatory function after facilitated percutaneous primary coronary angioplasty: the FINESSE-ANGIO (Facilitated Intervention with Enhanced Reperfusion Speed to Stop Events-Angiographic) study. JACC Cardiovasc Interv 2010, 3(12):1284-1291.

doi:10.1186/1471-2261-14-115

Cite this article as: Helve et al:: Trends in treatment delays for patients with acute ST-elevation myocardial infarction treated with primary percutaneous coronary intervention. BMC Cardiovascular Disorders 2014 14:115.

\section{Submit your next manuscript to BioMed Central and take full advantage of:}

- Convenient online submission

- Thorough peer review

- No space constraints or color figure charges

- Immediate publication on acceptance

- Inclusion in PubMed, CAS, Scopus and Google Scholar

- Research which is freely available for redistribution 